
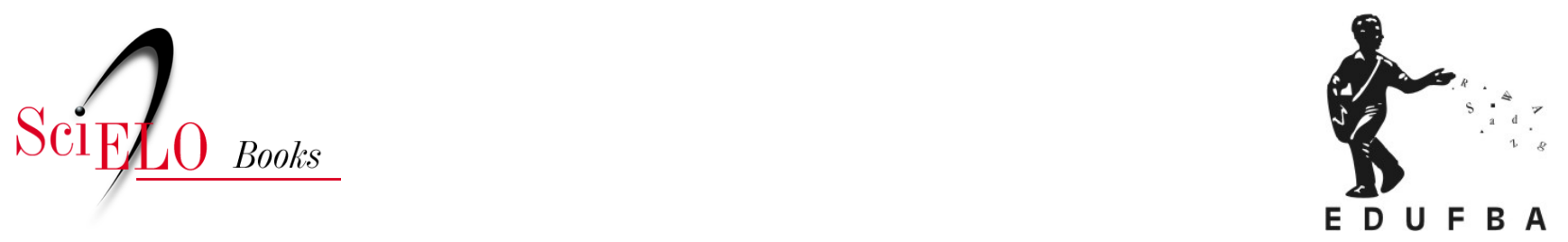

\title{
Parte II - Propostas de ensino \\ Pesca da lagosta: questões sociocientíficas no contexto de uma intervenção de educação ambiental multicultural em comunidade tradicional
}

Clívio Pimentel-Júnior

Wellington Bittencourt

\section{SciELO Books / SciELO Livros / SciELO Libros}

PIMENTEL-JÚNIOR, C., and BITTENCOURT, W. Pesca da lagosta: questões sociocientíficas no contexto de uma intervenção de educação ambiental multicultural em comunidade tradicional. In: CONRADO, D.M., and NUNES-NETO, N. Questões sociocientíficas: fundamentos, propostas de ensino e perspectivas para ações sociopolíticas [online]. Salvador: EDUFBA, 2018, pp. 173-189. ISBN 978-85232-2017-4. https://doi.org/10.7476/9788523220174.0008. \section{International license.}

All the contents of this work, except where otherwise noted, is licensed under a Creative Commons Attribution 4.0

Todo o conteúdo deste trabalho, exceto quando houver ressalva, é publicado sob a licença Creative Commons Atribição 4.0. 


\title{
PESCA DA LAGOSTA \\ QUESTÕES SOCIOCIENTÍFICAS NO CONTEXTO DE UMA INTERVENÇÃO DE EDUCAÇÃO AMBIENTAL MULTICULTURAL EM COMUNIDADE TRADICIONAL
}

\author{
Clívio Pimentel-Júnior \\ Wellington Bittencourt
}

\section{Introdução}

O capítulo em pauta apresenta uma proposta de intervenção pedagógica baseada em Questões Sociocientíficas (QSC) elaborada com base nos problemas socioambientais vivenciados pelos moradores do vilarejo de Garapuá, município de Cairú, Bahia. A QSC foi pensada para ser aplicada em uma mostra de cinema nacional, o Cine Garapuá (ver Figura 1); porém é importante ressaltar que pode ser utilizada, com adaptações, em outros contextos similares de educação formal e não-formal onde problemáticas socioambientais sejam evidentes. Será tratada, assim, como uma intervenção artístico-pedagógica de educação ambiental que já acontece no referido município, em um espaço educacional não-formal. ${ }^{1}$

1 De acordo com Gohn (2010), espaços educacionais não formais são marcados por ações de coletivos sociais que interagem segundo diretrizes do grupo com propósito de resolver problemas e questões comuns. Nesse contexto de negociações constantes, emergem condições e valores de pertencimento, consciência e organização em coletividade para o enfrentamento de problemáticas reais e criação de alternativas aos constrangimentos cotidianos. Neste trabalho, usamos o 
Figura 1 - Exibição do filme Tainá: a origem, para crianças da comunidade, no Cine Garapuá

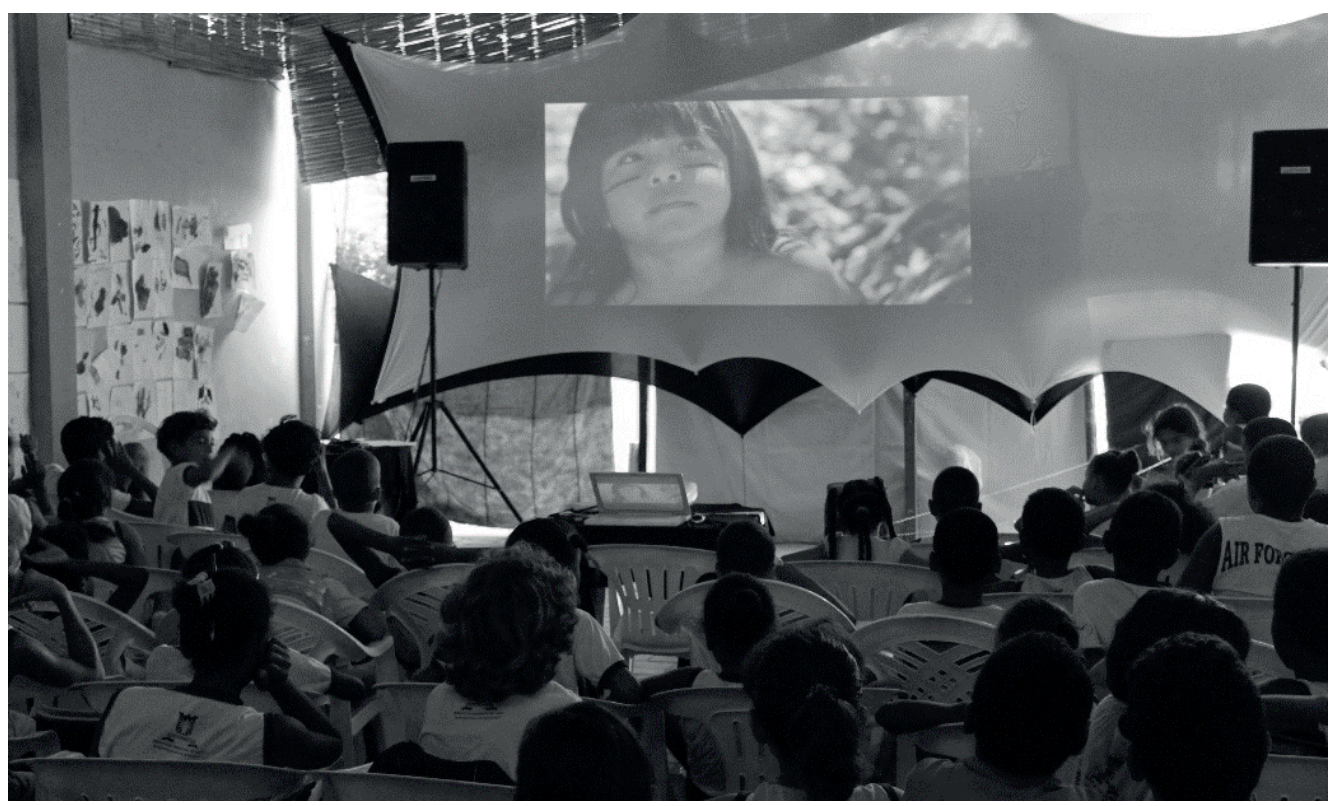

Fotógrafo: Lucas Viana.

O projeto Cine Garapuá teve sua primeira edição em 2014, sendo coordenado pela mesma equipe do Cine Capão, que já acontece há sete anos, no Vale do Capão, Chapada Diamantina, Bahia. Além da mostra de cinema brasileiro, o Cine Garapuá realizou em conjunto oficinas de audiovisual, stop motion e grafite, todos voltados à temática ambiental, para um público de crianças, adolescentes e adultos da comunidade de Garapuá. O projeto foi aprovado pelo Edital Setorial de Audiovisual do Fundo de Cultura do Estado da Bahia (Funceb) e contou com apoio da Prefeitura Municipal de Cairú, através da Secretaria de Educação, Secretaria de Assistência Social e Assessoria de Comunicação de Cairú, em que se estabeleceu o acordo de apoios e as autorizações para a realização do projeto, em benefício dos alunos da Escola Municipal José Gomes de Aragão - ensino médio e Educação de Jovens e Adultos (EJA) - e Escola Creche Dirce de Souza. O projeto teve como intento maior promover uma discussão a respeito das relações da comunidade de moradores da região com os seus ambientes naturais e, deste modo, sensibilizá-los para a necessidade de um desenvolvimento mais responsável na região. ${ }^{2}$ Devido

termo "não-formal" para se referir ao espaço educativo em questão por se tratar de um projeto de intervenção artístico-pedagógico de cunho socioambiental que visa fomentar ações sociopolíticas coletivas, para além do ambiente escolar, no enfrentamento de problemas reais comuns.

2 Informações mais detalhadas e fotos das ações do grupo podem ser visualizadas através de algumas redes sociais, como: Cine Garapuá. Facebook. 21 mar. 2014. Disponível em: <https://www.facebook. com/cinegarapua?fref=ts>. Acesso em 22 out. 2015; Cine Garapuá - making of. Youtube. Disponível em: <https://www.youtube.com/watch?v=LV3DKfy9RSo>. Acesso em: 22 out. 2015, Na trilha do 
às peculiaridades do contexto eleito para nossa intervenção, assumimos dois grandes desafios, os quais são, em certo sentido, inaugurais:

- $\quad$ o intento de elaborar uma QSC para a aplicação no âmbito educacional não-formal, visto que, até então, não encontramos referências na literatura do tratamento de QSC fora do espaço de educação escolar; e

- a particularidade de aplicar tal estratégia didática no contexto sociocultural de uma comunidade tradicional, o que evoca a questão do diálogo entre diferentes formas de saberes.

Apesar das dificuldades enfrentadas na recontextualização e na ampliação dos domínios de aplicação de uma ferramenta pedagógica, assumimos a ideia de que "acorrentar as concepções do professor a monolíticos estratagemas, propagados pelos programas pedagógicos, não é produtivo para sua praxe profissional criativa, assim como, limita, ou mesmo fossiliza a sua reflexão crítica, a sua imaginação". (LABURÚ; ARRUDA; NARDI, 2003, p. 254) Sob tal perspectiva, a QSC configura-se uma estratégia de intervenção pedagógica aplicável no contexto do projeto de educação socioambiental multicultural.

Do nosso ponto de vista, tornou-se fundamental compreender a singularidade cultural da comunidade para que pudéssemos desenvolver uma proposta de educação participativa que privilegiasse a diversidade de saberes. Através de um viés etnoecológico (DIEGUES, 2004), buscamos refletir a sustentabilidade no contexto das diferenças culturais. Partimos da compreensão de que, nas comunidades tradicionais, a degradação ambiental e a erosão de elementos da identidade cultural contribuem concomitantemente para a desagregação destes grupos sociais, conduzindo-os a consolidar posições de dependência e impotência frente à dominação da "monocultura do produtivismo capitalista”. (SANTOS, 2007, p. 31) Consideramos que muitas das questões socioambientais da comunidade tradicional de Garapuá poderiam ser criticamente apreendidas através do emprego da QSC. Deste modo, ela se configurou como estratégia didática para discutir as relações da comunidade com a manutenção dos seus ambientes, de modo a sensibilizá-la para um manejo socioambiental responsável na região.

Ainda que construída com base nestes aspectos, estamos atentos também às relações entre espaços não formais e formais de ensino. Defendemos que o campo da educação não-formal não apenas dialoga como reafirma a importância da educação formal via escolarização. Dessa forma, é importante nos precaver para que o espaço da educação não-formal não seja construído pela negação da escola. (AFONSO, 2001; GOHN, 2010) Em paralelo, trata-se de reconhecer que, para além do ambiente escolar - que, sozinho, não dá conta da formação dos indivíduos e dos coletivos sociais -, o processo de construção de conhecimento se dá em diversos contextos sociais, seja no seio familiar, nos

curta - Garapuá antes e depois. Youtube. Disponível em: <https://www.youtube.com/watch?v=S0jLcJamMll>. Acesso em: 22 out. 2015. 
ambientes de lazer, nos museus, em ambientes religiosos, centros culturais, Organizações Não Governamentais (ONG) etc. (BURNHAM, 2005) Assim, é importante destacar as ações educativas não formais como modo de ampliação de acesso da população à cultura científica bem como sua participação nela (GOHN, 2010) e a importância da apropriação deste referencial cultural na tomada de decisão para ação social responsável (SANTOS; MORTIMER, 2001), condizente com a ideia de cidadania ${ }^{3}$ (HODSON, 2004), para o enfrentamento coletivo de problemáticas socioambientais reais.

A problemática socioambiental, abordada neste trabalho por meio da QSC abaixo apresentada, diz respeito à relação entre a pesca e o consumo da lagosta na região de Garapuá. Nessa discussão, compreendemos que "[O] que deve ser considerado prioritariamente são as relações econômicas e culturais entre a humanidade e a natureza e entre os homens, possibilitando a ampliação da participação política dos cidadãos". (REIGOTA, 1994, p. 9) O critério de escolha deste tema para estruturar a QSC partiu da interpretação das relações simbólicas, econômicas, turísticas e gastronômicas que têm tradicionalmente girado em torno da pesca e do consumo da lagosta na região. Trata-se de uma aposta na ideia de que, ao interpretar essas relações e representá-las por meio de uma história fictícia, isto é, com potencial representativo dos conflitos vivenciados pelos moradores da região, despertaremos o interesse coletivo em participar das tomadas de decisões necessárias ao enfrentamento dos problemas expostos. A partir do reconhecimento de suas histórias de vida, simbolicamente representadas no enunciado da QSC, almejamos fomentar valores relativos ao sentido de pertencimento entre os membros da comunidade e seus ambientes, de modo a promover ações sociopolíticas viáveis para o manejo equilibrado na comunidade.

Convém, neste momento, apresentar alguns aspectos da comunidade de Garapuá que servem de contextualização do tema socioambiental trabalhado. Esperamos que, ao fazê-lo, torne-se explícita a importância da realização de práticas de observações interpretativas sistemáticas dos cotidianos vivenciados a fim de identificar conflitos socioambientais com forte potencial mobilizador de interesse na resolução dos mesmos pelos sujeitos envolvidos. Um olhar atento, tanto às questões culturais locais quanto aos propósitos de uma educação científica em uma perspectiva humanística e sociopolítica,

3 De acordo com Hodson (2004), faz parte da educação para a cidadania a ideia que o aluno consiga participar ativamente de tomadas de decisão através das experiências proporcionadas pelo currículo escolar, a fim de fomentar a participação sociopolítica em relação aos problemas da comunidade (em escala regional), e problemas globais (em escala planetária). Nesse sentido, o professor e a instituição escolar são responsáveis por fomentar nos alunos posturas contestadoras, construtivas, solidárias e comprometidas com o bem-estar individual e coletivo através do empoderamento, via currículo, convidando-os a tomar decisões referentes, por exemplo, ao contexto escolar, proporcionais ao seu nível de desenvolvimento. Por exemplo, pode-se mencionar projetos de controle da quantidade de energia gasta na escola, da quantidade de papel gasto nas atividades etc. Para ele, educar para a cidadania é manter em mente as consequências de nossas ações em contextos locais, passíveis de avaliação mais explícita, que oferecem ocasiões concretas para atuações responsáveis - e, por isso mesmo, empoderadoras -, articuladas com contextos globais. 
mostrou-se necessário a fim de aumentar o interesse do público nas questões científicas e no uso responsável da ciência. (AIKENHEAD, 2006; HODSON, 2004)

O vilarejo de Garapuá está localizado na ilha de Tinharé, possui economia baseada na pesca e no turismo e sua população não ultrapassa 800 habitantes. Sendo uma localidade de difícil acesso, a comunidade tem pouco contato com a produção cinematográfica nacional, não dispondo de cinema, vídeolocadora ou cineclube; a ilha já dispõe de conexão à internet ainda com uma utilização restrita pelas pousadas e para os turistas. Ou seja, a comunidade possui, de modo restrito, uma cultura audiovisual baseada quase que exclusivamente na televisão aberta.

Os municípios que fazem parte do Território de Identidade do Baixo Sul, em especial, o município de Cairú, possuem um potencial natural que abriga belíssimas áreas de preservação ambiental com ricos ecossistemas - a exemplo dos mangues, florestas tropicais e recifes de corais. Atualmente, Garapuá tem vivenciado um processo de forte especulação imobiliária, caracterizada pelo loteamento de grandes propriedades e subsequente venda dos lotes para imigrantes de outras regiões do país e estrangeiros. As dinâmicas econômicas decorrentes de tal processo especulativo podem ser e, de fato, têm sido prejudiciais à preservação e ao manejo dos ambientes da região. Na última década, o aumento expressivo da atividade turística vem exercendo fortes pressões na fisionomia ambiental da região, levando a agressões cuja extensão e velocidade não têm deixado oportunidade para a regeneração natural dos ecossistemas; além do impacto sociocultural que vem transformando a dinâmica da comunidade. (FRANCO, 2002)

Dentre as diversas atividades turísticas, que envolvem os ecossistemas naturais, praticadas na região, estão as visitações às piscinas naturais formadas periodicamente nos recifes, de acordo com os movimentos da maré e da dinâmica pluvial na região. As visitações são agendadas com guias turísticos ou diretamente com moradores e donos de barco na região, de acordo com estas informações. Atrelada a essa visitação, encontramos a atividade gastronômica voltada para o consumo da lagosta, amplamente ofertada e, segundo os moradores, por um preço que não se encontra facilmente nas áreas urbanas e regiões metropolitanas; de onde, aliás, provém a maioria dos turistas que visitam Garapuá. Acontece que, por um lado, a alta demanda de lagostas decorrentes do aumento do número de turistas tem movimentado significativamente a atividade econômica da região e garantido a subsistência de muitas famílias. Mas, por outro lado, técnicas ilegais de pescas aliadas a pescas em períodos de reprodução da lagosta têm se tornado práticas recorrentes na região com vistas a atender tal demanda. Esse consumo e pesca predatório e, em alguma medida, ilegal têm culminado numa maior dificuldade de encontro da lagosta na região, o que tem levado os pescadores a arriscarem frequentemente suas vidas, seja por meio de técnicas ilegais e arriscadas de pesca e mergulho, seja pela distância cada vez maior a percorrer mar adentro para a pesca da lagosta.

O problema, portanto, está colocado: como a educação científica pode contribuir no enfrentamento da problemática socioambiental, política e cultural em questão, por 
meio de práticas de educação não-formalmente estruturadas em QSC? Embora a QSC tenha sido elaborada com base na problemática vivida pelos moradores de Garapuá, reforçamos que esta pode ser aplicada em outras comunidades, tradicionais ou não, com problemas socioambientais semelhantes. Para tanto, adaptações demandadas pelo contexto ambiental, político e cultural local deverão ser feitas pelo educador no ambiente não-formal. Acreditamos, além disso, no seu potencial formativo em espaços formais de aprendizagem, ampliando o âmbito de aplicação desta QSC ou outras similares, contextualmente adaptadas pelo professor de ciências, para a sala de aula.

Apesar de este ser um problema socioambiental complexo, neste trabalho, ele será abordado prioritariamente do ponto de vista educacional; portanto, não pretendemos esgotá-lo por meio das discussões aqui apresentadas. Isto restringe o nosso objetivo em apresentar uma QSC elaborada, que envolve a problemática acima descrita, ao lado de conhecimentos específicos em biologia, ciências naturais, etnoecologia, ética ambiental, oceanografia e geografia, bem como meios para sua aplicação em espaços educacionais não formais com vistas a fomentar tomadas de decisões socialmente responsáveis e ações sociopolíticas.

A compreensão das relações simbólicas no Vilarejo de Garapuá bem como a busca por uma abordagem humanística da ciência, efetiva em termos comunicacionais, foram critérios determinantes para adentrarmos no campo dos estudos culturais como meio de superar uma possível abordagem cientificista. Além de limitante, de um ponto de vista pedagógico e comunicacional, essa abordagem expressa um colonialismo cultural catequizante. (BHABHA, 1998; GARCIA CANCLINI, 2008; SANTOS, 2006, 2007) Os estudos culturais têm apresentado forte potencial heurístico, quando se trata da compreensão de como se hibridizam ${ }^{4}$ conhecimentos científicos com saberes culturais cotidianamente forjados (CARVALHO et al., 2014) na formação de novas práticas culturais. Em termos pedagógicos e em consonância com as discussões de Bizzo (2009), apresentamos algumas orientações etnometodológicas e pedagógicas relevantes na aplicação desta QSC em espaços educacionais não formais de ensino, que traduzem a importância desses estudos no campo da educação não-formal e no ensino de ciências.

\section{Os estudos culturais e a aplicação de QSC em espaços educacionais não formais}

Pretendemos desenvolver, nesta seção, argumentos que apresentam noções provenientes da combinação de estudos culturais e sociológicos. Do nosso ponto de vista,

4 As dinâmicas de hibridismo cultural são entendidas como processos que "produzem misturando bens culturais e temporalidades históricas distintas que convivem num mesmo presente" (GARCIA CANCLINI, 2008, p. 56-83) e podem culminar na exigência e na negociação de novas formas de pensamento e ação. Esta forma de encarar a construção do conhecimento exige, por sua vez, nova forma de encarar os processos de aprendizagem, mediante ecologias intelectuais na construção de argumentos. (BIZZO, 2009; CARVALHO et al., 2014) 
tais argumentos são necessários para viabilizar a aplicação de QSC em espaços educacionais não formais. Recorremos às teorizações críticas pós-coloniais e culturais representadas nos estudos de Bhabha (1998), Santos (2006, 2007), Garcia Canclini (2008) e Certeau (2009) como forma de nos afastarmos do cientificismo, ${ }^{5}$ pois este tem sido impeditivo na construção de ambientes interativos em espaços educacionais não formais, com vistas a potencializar ações sociopolíticas coletivamente organizadas para o enfretamento de problemas reais. (GOHN, 2010) As perspectivas pós-coloniais, de acordo com Bhabha (1998, p. 239), formulam suas revisões críticas em torno de questões de diferença cultural, autoridade social e discriminação política, testemunhando as forças desiguais e irregulares de representação cultural envolvidas na competição pela autoridade política e social dentro da ordem do mundo moderno. Para o autor, toda a gama de teorias críticas contemporâneas sugere que é com aqueles que sofreram o sentenciamento da história - subjugação, dominação, deslocamento, invisibilidade - que aprendemos nossas lições mais duradouras de vida e pensamento. Isto é, segundo o autor, há uma convicção crescente de que a experiência afetiva da marginalidade social tem transformado as estratégias críticas, fazendo-as girar em torno da credibilidade de práticas simbólicas produzidas no ato da sobrevivência social dos que estão à margem. (BHABHA, 1998, p. 240)

Por sua vez, em Santos $(2006,2007)$, a sociologia crítica toma a forma de posicionamentos político-epistemológicos democráticos, operados por meio dos procedimentos sociológicos da tradução, da sociologia das ausências e das emergências. Para o autor, o trabalho de tradução aliado aos outros dois procedimentos sociológicos referidos constituem formas de combate à ocultação e ao descrédito sofrido pelas experiências sociais que transcendem a compreensão ocidental do mundo, sua tradição científica e/ou filosófica. Em suas palavras, "só assim, será possível criar o espaço-tempo para conhecer e valorizar a inesgotável experiência social que está em curso no mundo de hoje”. (SANTOS, 2006, p. 780) Ressaltamos, para os propósitos deste trabalho, a importância da tradução. Para Santos (2006, p. 804), a tradução pode criar interfaces dialógicas entre sistemas culturais e toma como ponto de partida a ideia de que todas as culturas são incompletas e, portanto, podem ser enriquecidas pelo diálogo e pelo confronto com outras culturas. As traduções ocorrem mediante as zonas de contato, que são "[...] campos sociais onde diferentes mundos-da-vida normativos, práticas e conhecimentos se encontram, chocam e interagem". (SANTOS, 2006, p. 808) Convém, nesse sentido, estar atento ao que surge a partir desses encontros e interações, em termos de saberes, no intuito de perceber potencialidades para

5 De acordo com Santos (2006), é possível caracterizar o cientificismo como uma ideologia totalitária que vê no conhecimento científico seu único ponto de ancoragem no que tange à confiabilidade e à credibilidade política e social, o que invariavelmente culmina numa ambiência propícia à emergência de uma "monocultura do saber e do rigor científico" (SANTOS, 2007, p. 29) impeditiva na criação de interfaces dialógicas entre saberes. 
tomadas de decisão socialmente referenciadas e coletivas, visando fomentar ações sociopolíticas viáveis para o enfrentamento coletivo de problemas reais.

Estes estudos socioculturais nos inspiraram a produzir algumas orientações etnometodológicas e pedagógicas combativas ao cientificismo e, a nosso ver, imprescindíveis como meio de viabilizar a aplicação de QSC em espaços educacionais não formais, neste caso, em comunidades tradicionais. Trata-se de orientações que se afastam de posturas soberbas e corretivas que impedem a construção coletiva de uma ambiência pedagógica respeitosa e produtiva, comprometida com as ações sociopolíticas necessárias ao enfrentamento das questões socioambientais e, ao mesmo tempo, atenta às diferenças culturais:

- nas dinâmicas socioculturais contemporâneas, marcadas pelo entrecruzamento de fronteiras e referenciais de leitura de mundo diversos, torna-se antidemocrático transformar a competência científica em autoridade, ao querer falar em nome do suposto "nativo" observado, tomado como objeto que nada tem, de útil e racional, a dizer, e que apenas deve seguir orientações;

- $\quad$ em consonância com Certeau (2009, p. 248), na investigação e nos estudos das "maneiras de viver" cotidianas de praticantes culturais, "é sempre bom lembrar que não se deve tomar os outros por idiotas”. Em outras palavras, é desfazer-se da ideia de que a relação dos praticantes com sua cultura é sempre inconsciente, irrefletida e alienada e o papel do investigador-intérprete, portador da competência técnico-científica, é esclarecer, decifrar, dominar e corrigir;

- evitar atribuições pejorativas de bens simbólicos à cultura popular/tradicional, sem esclarecer as diferenças entre senso comum e práticas cotidianas de uma cultura. Essa atribuição pejorativa, ao se desarticular de uma diferenciação entre os saberes, pode culminar em "limpezas culturais" de efeito homogeneizante ao se adotar a posição da "ciência correta", baseada em falsas oposições entre saberes.

Compartilhamos, com as perspectivas críticas e pós-coloniais, posicionamentos radicalmente opostos às abordagens cientificistas. $O$ processo de criação de interfaces dialógicas entre saberes é uma das ideias estruturantes das perspectivas educacionais pluralistas (AFONSO, 2001; BURNHAM, 2005; GOHN, 2010) que, dentre outros aspectos, reconhecem os espaços não formais como campos férteis na potencialização do interesse público nas questões científicas e no uso responsável e emancipatório da ciência. A criação de "pontes de diálogo" entre diferentes visões de mundo e saberes, por sua vez, exige abordagens pedagógicas combativas às abordagens de cunho homogeneizante, como o cientificismo. Consideramos, portanto, imprescindível para a viabilização da proposta desenvolvida que abordagens cientificistas sejam superadas como 
forma de criar uma "ambiência coletiva" pedagogicamente propícia à recepção, à apropriação e ao uso dos conhecimentos que aí se chocam e interagem, não sem conflitos, na fundamentação de ações coletivas socialmente referenciadas e reivindicatórias. Dessas atitudes reivindicatórias que se espera fomentar, decorre outro aspecto importante a destacar, no sentido de superar um tratamento que reduz a solução do problema à simples apropriação de conhecimentos. Ao lado da dimensão educativa, e tendo ela como alavanca propulsora, a análise e a resolução do problema observado requerem também uma ampla participação da comunidade local. Isto é, requerem uma mobilização coletiva no sentido de canalizar reivindicações acerca de investimentos que possibilitem a diversificação das atividades econômicas e de subsistência na região e direcioná-las às esferas políticas que a governam. Trata-se de reconhecer que o problema estudado está para além da relação entre o sujeito e o conhecimento e requer um olhar complexo a fim de evitar injustiças sociais sob a alegação de "ignorância”. Defendemos que o problema - ainda que tenha uma dimensão epistemológica - não é um problema puramente epistemológico, mas, sobretudo, social e político.

\section{QSC em espaços educacionais não formais e construtivismo contextual}

As orientações etnometodológicas desenvolvidas, na seção anterior, estão em consonância com a perspectiva do construtivismo contextual (COBERN, 1996, 2013) e do aprender ciência enquanto aquisição de cultura. (AIKENHEAD, 2006, 2009) São perspectivas que, de modo geral, se afastam da leitura colonialista de que as culturas e os saberes das comunidades tradicionais apresentam apenas "influências potencialmente adversas em relação aos interesses e avanços da ciência”. (COBERN, 1996, p. 6) De acordo com essas perspectivas, a aprendizagem em ciências envolve negociações e interpretações entre "visões de mundo" que engendram e são engendradas via processos socioculturais. Disto, decorre que aprender ciência significa "entrar numa nova cultura cruzando fronteiras". (AIKENHEAD, 2009, p. 90) Transitar entre diferentes culturas, no entanto, pode ser uma tarefa complexa e difícil para os interessados no mundo cultural da ciência, pois, muitas vezes, é vista como uma cultura estranha, alheia aos saberes úteis na resolução das necessidades cotidianas. (AIKENHEAD, 2009; CARVALHO et al., 2014; COBERN, 1996) Nesse sentido, o desafio de uma perspectiva de educação em ciências comprometida com as questões culturais e com os complexos "cruzamentos de fronteiras" pode ser traduzido por meio da ideia de "fornecer abrigo" (CARVALHO et al., 2014) àqueles que, na cultura científica, reivindicam o lugar de formas diferentes de uso da ciência em interação com outras visões de mundo. Como é possível "abrigar" as diferentes formas de "cruzamentos de fronteiras" entre a visão de mundo científica e outras visões de mundo que emergem no contato intercultural? Questionamentos desse tipo têm levado investigadores (AIKENHEAD, 2009; BIZZO, 2009; CARVALHO et al., 2014) 
a defender os "cruzamentos de fronteiras" como momentos marcados pela coexistência de preconcepções culturalmente forjadas com concepções científicas nas construções intelectuais. São momentos de construção de conhecimento caracterizados por "ecologias intelectuais" (BIZZO, 2009, p. 64) nas atividades de argumentação marcadas por hibridismos culturais.

Compreendendo a noção de hibridismo como estruturante das dinâmicas de "cruzamentos de fronteiras" entre visões de mundo, optamos, neste capítulo, por produzir algumas orientações pedagógicas, pensando tanto em espaços educacionais formais e, sobretudo, em não formais, como modo de viabilizar a aplicação da proposta de ensino baseada em QSC abaixo exposta de modo mais dialógico e propositivo, no que diz respeito à apropriação para a ação sociopolítica:

- nas conversações que se estabelecem nos espaços educacionais não formais, convém estar atento às argumentações construídas por meio de processos de hibridismo de referências, marcados por "ecologias intelectuais" na fundamentação de tomadas de decisão para a ação social responsável. Construções argumentativas marcadas por hibridismos se apresentam na forma de teias de relações entre os conhecimentos pré-existentes e os adquiridos, numa construção que mescla argumentos oriundos da percepção de mundo e do contato com conceitos científicos mais abstratos na fundamentação das ações. A aceitação e o reconhecimento desses argumentos, sobretudo em espaços educacionais não formais, podem não apenas potencializar o interesse para a visão de mundo científica, mas mobilizar para tomadas de decisão para ações responsáveis viáveis;

- sobretudo, mas não exclusivamente, em espaços educacionais não formais, cuja heterogeneidade dos grupos é algo evidente, convém estar atento aos "estados de cidadania"6 (BURNHAM, 2005) dos indivíduos, a fim de compreender a diversidade de "situações de cidadania" que, por sua vez, implicam em diversos níveis de participação sociopolítica. Trata-se de evitar injustiças sob a alegação de suposta "igualdade" de participação sociopolítica dos indivíduos nas sociedades complexas marcadas por vários níveis de exclusão social.

6 Segundo Burnham (2005), o termo "estado" é empregado como alternativa a "estrato", considerando que este último oferece uma ideia estática, de divisão permanente, separação sem interação, enquanto o primeiro permite a ideia de "estar sendo", num determinado momento, possibilitando mobilidade. O que se busca traduzir com o esquema referencial de "estados de cidadania" é o empenho de não aceitar dicotomias que escondem exploração, desrespeito e desigualdade na invisibilidade das diferentes formas e, sobretudo, condições de viver a cidadania e a democracia nas sociedades complexas, marcadas por desigualdades que vão desde a excludente privação ao acesso às condições mínimas de necessidades imediatas, até a participação instituinte nas esferas produtivas, políticas culturais e ambientais. 
Nas próximas seções, apresentamos a QSC desenvolvida por nós a partir do problema socioambiental observado no vilarejo de Garapuá, bem como algumas considerações finais em torno da defesa de uma educação científica para ação sociopolítica com aportes da socioantropologia crítica e pós-colonial.

\section{Uma QSC do mar}

Como dito, esta QSC e as orientações expostas acima foram produzidas a partir de um problema socioambiental vivenciado por moradores do Vilarejo de Garapuá. Trata-se de um contexto marcado por uma heterogeneidade evidente de pessoas com faixas etárias e níveis de escolaridade distintos, interesses pessoais e coletivos diferentes e, muitas vezes, divergentes, filiações políticas e ideológicas as mais diversas. Apesar de construída com base nestes aspectos, entendemos que este problema envolve questões educacionais, políticas e culturais que estão para além daquele contexto específico de ocorrência, sendo, portanto, possível encontrar outros espaços educacionais, formais e não formais, onde esta proposta seja aplicável. Pensando a educação científica no cenário brasileiro, que dispõe de uma costa marinha extensa, na qual os ecossistemas vêm sendo historicamente explorados, convém refletir as relações sociais, econômicas e ambientais envolvidas nestes processos predatórios. Esta QSC, por trabalhar com este tema, torna-se uma ferramenta útil para compreender tais problemas nos mais variados contextos.

No que diz respeito aos espaços educacionais formais, convém estar atento aos níveis de ensino a que serão destinados esta proposta: consideramos conveniente a aplicação desta QSC a partir dos anos finais - $8^{\circ}$ e $9^{\circ}$ anos - do ensino fundamental, bem como ensino médio, técnico e Educação de Jovens e Adultos (EJA), podendo ser abordado por diferentes disciplinas e até mesmo numa perspectiva interdisciplinar, dado seu caráter complexo e mobilizador de diferentes áreas do conhecimento, dentre as quais destacamos: ciências naturais, em aulas voltadas ao tema meio ambiente, dentre eles o marinho, podendo atrelar a discussão ao consumo de crustáceos e à conservação socioambiental; e/ou em etnoecologia, para refletir questões de configuração ambiental numa relação integrada às dinâmicas das comunidades; e/ou em ética ambiental, para problematizar questões de valores na educação, fomentando a conscientização socioambiental. No ensino superior, essa QSC também poderá ser aplicada, resguardando devidas adaptações para o contexto e os objetivos da disciplina.

O enunciado da QSC foi construído envolvendo personagens com potencial representativo das relações simbólicas que lá foram observadas e traduzidas por nós, por meio de um caso (Quadro 1). Logo após, apresentamos algumas questões relacionadas ao caso, seguidas dos objetivos de aprendizagem sugeridos. 
Quadro 1 - QSC sobre a pesca da lagosta, na forma de caso

Pesca da lagosta: uma QSC do mar

Rai, pescador e morador da região de Garapuá, com alto prestígio e respeito pelos demais membros da comunidade, devido à sua habilidade e competência em trazer "o barco cheio", foi comunicado pelos donos de restaurantes e agências de viagem que as piscinas e praias de Garapuá estão no roteiro de viagem de diversos pacotes turísticos fechados para o período de 5 de janeiro a 5 de março. Rai, sabendo da demanda, sobretudo da lagosta que está colocada nos folders turísticos da região, prontamente reuniu um grupo de pescadores e partiu pro mar; é época de barco cheio! O grupo de Rai, sabendo da dificuldade da alta demanda, optou por ir realizar a pesca em águas mais profundas, por meio do uso de compressores. Conversando com Rai, os pescadores falaram desta escolha, quando um deles disse:

- Mas você não ficou sabendo da história com o sobrinho de Zé Carlos, não? Essa história de pescar com compressor tá matando muita gente no mar... É perigoso...

Outro pescador do grupo replicou:

- Mas o que a gente vai fazer, se tá ficando cada vez mais difícil e, a cada ano que passa, a gente precisa ir mais longe pra conseguir pegar uma lagosta? Todo mundo sabe que o verão tá vindo aí e os turistas vão chegar querendo lagosta, é nossa oportunidade de ganhar um dinheirinho... Eu mesmo tô querendo aproveitar esse verão para dar um jeito no meu terreno, quero botar pra vender e precisa dar um trato nele... Tem sempre uns gringos querendo comprar...

Contudo, segundo regulamentação do Instituto Brasileiro do Meio Ambiente e dos Recursos Naturais Renováveis (Ibama), no que se refere à lagosta, a pesca é proibida no período de $1^{\circ}$ de dezembro até o dia 31 de maio. Rai sabe que o pescador que pegar lagosta nesta época pode pagar multa de até 100 mil reais e pode ficar preso por até 3 anos. Valmir, dono de um dos restaurantes da região, por sua vez, sabe que só pode vender a lagosta que estiver estocada, mediante apresentação do certificado de estocagem, garantindo que o animal tenha sido capturado antes do período de proibição, estando sujeito a multas e fechamento do estabelecimento. Jandira, esposa de Valmir, anda preocupada com a fiscalização e, junto com outras moradoras, começa a produzir doces artesanais, aproveitando a fartura das frutas típicas da região. Insiste em alertar seu marido:

- Val, essa pescaria de lagosta, nessa época, ainda vai dar problema!

Tentando convencê-lo, lembra-o do exemplo de Dona Ana, que tem ganhado um bom dinheiro todo verão, vendendo artesanato e roupas de renda que ela mesma faz em casa.

Ezequiel, guia turístico, responsável pelos pacotes fechados, é o tutor que acompanha os turistas na visitação às praias e piscinas naturais, locais onde tradicionalmente mais se consome a lagosta. Daniel integra o primeiro grupo de turistas a desembarcar na costa de Garapuá e desconhece as legislações ambientais de pesca da lagosta. Conversando entusiasmado com seus amigos, ele diz:

- Não vejo a hora da gente chegar nesse paraíso e se jogar na beira da praia pra ficar comendo lagosta na manteiga o dia inteiro! Ouvi falar que lá a gente pode comprar lagosta por um precinho bem barato, impossível de encontrar nos restaurantes de outros lugares.

Fonte: elaborado pelo autores com base em Pimentel-Júnior (2015).

\section{Questões do caso sobre a QSC}

Q1. Na posição de Rai, como você argumentaria com Valmir, dono do restaurante, e Ezequiel, guia turístico, em relação aos problemas da pesca da lagosta no período de alta estação indicado?

Q2. Na posição de Valmir, como você argumentaria com Rai e Ezequiel diante das demandas turísticas de consumo da lagosta? 
Q3. Na posição de Ezequiel, como você argumentaria com Daniel, turista passageiro em Garapuá, diante das relações de consumo da lagosta nesse período?

Q4. Na posição de Daniel, como você argumentaria com Valmir diante da oferta de lagosta nos cardápios dos restaurantes de Garapuá?

Q5. O que você acha do posicionamento de Dona Jandira? Quais outras alternativas socioeconômicas poderiam ser pensadas para substituir a pesca da lagosta durante o período de interdição?

Q6. Por que o trabalho dos pescadores pode ser perigoso? Quais são os riscos à saúde a que eles estão expostos? O que poderia ser feito para minimizar tais problemas?

Q7. Como você explica a observação do pescador que, a cada ano, fica mais difícil encontrar as lagostas? Quais seriam as consequências ambientais e socioeconômicas que podem ser geradas por esse fenômeno? O que poderia ser feito para reverter esse quadro de desaparecimento progressivo das lagostas?

Q8. Se você fosse um membro da comunidade de Garapuá, diante dos problemas ambientais envolvidos na relação de consumo da lagosta, como você argumentaria com os demais membros da comunidade para que, coletivamente, agissem frente às questões sociais e ambientais envolvidas nessa atividade turística/gastronômica? Quais atitudes você fomentaria na comunidade diante dessa situação?

Q9. De que forma a arte e a cultura podem contribuir para a resolução dos problemas socioecológicos da região?

Q10. O que poderia ser feito para o desenvolvimento de um turismo socioecológico responsável na comunidade?

Q11. Diante de pressões socioambientais que têm reduzido a quantidade de lagostas na região, que outras formas de garantir a renda da população poderiam ser exploradas?

Objetivos de aprendizagem (ZABALA, 1998), com base em Pimentel-Junior (2015):

\section{Conceituais}

- Compreender as relações ecológicas do ecossistema marinho da região;

- Compreender noções básicas de bioética e educação ambiental como fundamento para uma educação ambiental estruturada em propostas proativas de resolução de problemas ambientais comunitários articulados a uma ética global;

- Compreender conceitos básicos de bioenergética do habitat marinho: fluxo de energia, pirâmide, cadeia e teias alimentares; 
- Compreender conceitos básicos de equilíbrio dinâmico ecológico e resiliência ambiental;

- Compreender conceitos básicos de ciclo reprodutivo das principais espécies relacionadas à teia alimentar;

- Compreender conceitos e princípios sobre a fisiologia da respiração e outros associados à saúde humana;

- Apresentar conceitos de senciência relativos à fisiologia e à filogenia da dor nos animais.

\section{Procedimentais}

- Desenvolver capacidade de análise e revisão dos métodos e práticas de pesca empregados na região;

- Desenvolver capacidade de reconhecimento das imbricadas relações entre meio e social da comunidade de Garapuá e levantamento das problemáticas relativas ao consumo da lagosta;

- Desenvolver capacidade de produção de projetos de "gestão local", articulando história natural e social da comunidade de Garapuá;

- Desenvolver e elaborar um código de conduta para a pesca responsável;

- Aperfeiçoar técnicas e procedimentos de segurança durante o mergulho.

\section{Atitudinais}

- Fomentar valores relativos ao "sentido de pertencimento", à "parceria com a natureza" e às "atitudes responsáveis" que, simultaneamente, viabilizam as atividades turístico-gastronômicas e o respeito à dinâmica natural dos ciclos de vida envolvidos;

- Dicutir a identificação de um mosaico de áreas especialmente protegidas para implantação de áreas marinhas de proteção em zonas de berçários e criadouros;

- Promover a cogestão dos ambientes marinhos como uma atividade integrada na comunidade;

- Fomentar a articulação e a parceria entre os pescadores e o Ibama para que sejam otimizadas as práticas de fiscalização; coibir a pesca de compressor e do uso da rede de espera (caçoeira), assim como a captura de lagostas juvenis em fase de desova;

- Discutir o licenciamento das frotas artesanais da região como instrumento de inclusão socioeconômica;

- Refletir e discutir sobre a consideração moral humana de animais sencientes, sobretudo com relação aos interesses secundários humanos (de gosto gastronômico), além dos problemas socioambientais gerados e mantidos pela pesca 
de crustáceos, associados também com uma discussão sobre ética não-antropocêntrica;

- Discutir efeitos da manutenção de determinadas práticas de alimentação na saúde humana e ambiental e quais tradições e atitudes da comunidade deveriam ser estimuladas, visando a melhoria na qualidade de vida dessas comunidades e do meio natural;

- Discutir valores culturais e morais, dando maior ênfase aos aspectos éticos e políticos para o desenvolvimento de um pensamento crítico dos envolvidos;

- Compreender o código da legislação ambiental no que diz respeito à pesca das lagostas em território nacional.

\section{Considerações finais}

Neste capítulo, tomamos como objetivo descrever o contexto socioambiental e cultural de elaboração de uma QSC, discutindo meios de aplicação na educação formal e não-formal, visando aprendizagem de conteúdos conceituais, procedimentais e atitudinais implicados na formação de cidadãos para tomada de decisão para ação social responsável. Apresentamos argumentos, orientações etnometodológicas e pedagógicas com objetivo de orientar a aplicação desta ferramenta didática, tanto no espaço não-formal investigado, como em outros espaços educacionais formais e não formais. Defendemos que o modo culturalmente implicado de construção desta QSC pode apresentar forte potencial mobilizador de interesse e participação coletiva da comunidade, com vistas à estruturação de um espaço de debate deliberativo acerca das suas relações com seus ambientes. Os debates têm como objetivo buscar soluções socioeconômicas, culturais e ambientais viáveis para combater os problemas observados no vilarejo de Garapuá.

Desejamos que este trabalho auxilie no desenvolvimento de novas propostas comprometidas com a integração crítica das relações entre Ciência, Sociedade, Tecnologia e Ambiente (CTSA), principalmente no que concerne ao uso de alternativas criativas para a solução de problemas observados em contextos não formais. Permanecemos cônscios de que um dos grandes desafios educacionais na contemporaneidade diz respeito ao modo pelo qual o conhecimento científico possa dialogar com outras visões de mundo, garantindo-lhes espaço, ao passo que possa ser instrumentalmente útil e compreensível em variados contextos. A relevância destas questões esteve sempre em foco durante a elaboração da nossa proposta de ensino baseada em QSC e das orientações etnomedológicas e pedagógicas explicitadas. Ressaltamos que não foi nossa intenção descredibilizar os saberes tradicionais da comunidade. Ao contrário, introduzimos ideias alternativas para serem ressignificadas de acordo com as necessidades locais. Nesse sentido, o intuito passou também pela ampliação do repertório de possibilidades de ação efetiva no enfrentamento dos problemas socioambientais vivenciados pela comunidade. 
Finalmente, diante das inúmeras questões socioambientais e dos múltiplos extrativismos que se integram às cadeias produtivas da região, engendrando uma reestruturação sociocultural acelerada, almejamos o desenvolvimento de uma família de QSC. Tencionamos trabalhar a "QSC do mar" integrada com outras QSC, as quais seriam: a "QCS da terra", a "QSC do mangue" e a "QSC sociocultural". A ideia de produção de uma família de QSC surgiu a partir do reconhecimento dos diferentes níveis e áreas de conhecimentos envolvidos no problema observado que, por sua vez, exigem uma rede de QSC articuladas em torno dos conflitos socioambientais e culturais da comunidade. Esta pode ser uma oportunidade para refletir junto à comunidade nos processos de negociação que marcam as ações dos coletivos sociais e os processos de hibridismo cultural envolvidos na fundamentação dessas ações e na formação identitária.

\section{Referências}

AFONSO, A. J. Os lugares da educação. In: VON SIMSON, O. R. M.; PARK, M. B.; FERNANDES, R. S. (Org.). Educação não-formal: cenários da criação. Campinas: UNICAMP/Centro de Memória, 2001. p. 29-38.

AIKENHEAD, G. Educação científica para todos. Tradução de Maria Teresa Oliveira. Lisboa: Edições Pedago, 2009.

AIKENHEAD, G. Science education for everyday life: evidence-based practice. New York: Teachers college press, 2006.

BHABHA, H. K. O local da cultura. Belo Horizonte: Ed. UFMG, 1998.

BIZZO, N. Ciências: fácil ou difícil? São Paulo: Biruta, 2009.

BURNHAM, T. F. Da sociedade da informação à sociedade da aprendizagem:

Cidadania e participação sócio-política na (in)formação do trabalhador. In: ENCONTRO NACIONAL DE CIÊNCIA DA INFORMAÇ̃̃̃O, 6., 2005, Salvador. Anais... Salvador: ICI/UFBA, 2005.

CARVALHO, J. M. et al. Entrecruzando ciência e cultura nas práticas pedagógicas curriculares. Revista Teias, Rio de Janeiro, v. 14, n. 37, p. 130-142, 2014.

CERTEAU, M. de. A invenção do cotidiano: 1. Artes de fazer. 16. ed. Tradução de Ephraim Ferreira Alves. Petrópolis: Vozes, 2009.

COBERN, W. Constructivism and non-western science education research. International Journal of Science Education, London, v. 4, n. 3, p. 287-302, 1996.

COBERN, W.; MOLINA, A.; PEÑALOZA-J, G. Enseñanza de las ciencias y contextos culturales: um testemonio de vida. Revista Internacional de Investigación en Educación. Bogotá, v. 6, n. 12, p. 187-192, 2013.

DIEGUES, A. C. S. O mito moderno da natureza intocada. São Paulo: Hucitec, 2004. 
FRANCO, M. V. G. Partilhando saberes: educação ambiental na vila de Garapuá, município de Cairú-BA. 2012. 74 f. Trabalho de Conclusão de Curso (Graduação em Biologia) - Instituto de Biologia, Universidade Federal da Bahia, Salvador, 2002.

GARCIA CANCLINI, N. Culturas híbridas: estratégias para entrar e sair da modernidade. Tradução de Heloísa Pezza Cintrão, Regina Lessa. São Paulo: Edusp, 2008 .

GOHN, M. da G. Educação não-formal e o educador social. São Paulo: Cortez, 2010.

HODSON, D. Going beyond STS: towards a curriculum for sociopolitical action. The Science education review, [S.1.], v. 3, n. 1, p. 2-7, 2004.

LABURÚ, C. E.; ARRUDA, S. de M.; NARDI, R. Pluralismo metodológico no ensino de ciências. Ciência e Educação, Bauru, v. 9, n. 2, p. 247-260, 2003.

PIMENTEL-JÚNIOR, C. Educação científica para ação sociopolítica: elaboração e tratamento de questões sócio-científicas em espaços educacionais não formais. In: COLÓQUIO INTERNACIONAL DO MUSEU PEDAGÓGICO, 11, 2015, Vitória da Conquista. Anais... Vitória da Conquista: UESB, 2015. p. 3959-3972.

REIGOTA, O que é educação ambiental. São Paulo: Brasiliense, 1994.

SANTOS, B. de S. (Org.). Conhecimento prudente para uma vida decente: um discurso sobre as ciências revisitado. $2^{\text {a }}$ ed. São Paulo: Cortez, 2006.

SANTOS, B. de S. Renovar a teoria crítica e reinventar a emancipação social. São Paulo: Boitempo, 2007.

SANTOS, W. L. P. dos; MORTIMER, E. F. Tomada de decisão para ação social responsável no ensino de ciências. Ciência e Educação, Bauru, v. 7, n. 1, p. 95-111, 2001.

TAINÁ: a origem. Direção: Rosane Svartman. Produção: Pedro Rovai. Roteiro: Cláudia Levay. Intérpretes: Wiranu Tembé; Nuno Leal Maia; Mayara Bents e outros. [S.1.]: Sony Pictures, Telelmage, Quanta, Telecine Images, DownTown Images, 2013. (80 min.), son., color.

ZABALA, A. A prática educativa: como ensinar. Porto Alegre: Artmed, 1998. 